\title{
The Construction of Rural E-commerce and New-type Urbanization
}

\author{
Lifeng Duan
}

\author{
Shaanxi Polytechnic Institute; Xianyang 712000, China
}

\begin{abstract}
The 18th National Congress of the Communist Party of China put forward to persist the road to new-type urbanization with Chinese characteristics. As promoting new countryside construction in China, development of urbanization today has inevitably increased many problems. This paper mainly commences from those problems of new-type urbanization and attempts to explore the development prospects of rural e-commerce. Based on the analysis of challenges along the path of urbanization, the author has expressed his opinions, hoping to make a contribution to development of urbanization in China.
\end{abstract}

Keywords: e-commerce, urbanization, development prospects.

\section{Introduction}

With the rapid development of information industry today, information construction, which retains enormous influence on every profession and trade, has cultivated a series of new industries, including e-commerce; a typical new industry emerged in the 21 st Century. The e-commerce industry is playing a more and more important role along the path of promoting urbanization in our country. However, some conflicts have been caused between the traditional agriculture and the new e-commerce business.

The overall urbanization in China will be achieved in a near future with the premise that our whole society is making joint efforts to overcome difficulties.

\section{Difficulties along the Path of New-Type Urbanization}

\subsection{The obstruction of urbanization development: rural areas are sparsely populated.}

In rural areas, regional population distribution is not dense enough and this characteristic is becoming an obvious obstruction of urbanization. In some areas, people choose to quicken their paces so they can achieve a rapid progress of development rather than considering the realities. That incorrect way of thinking leads to the unreasonable regional spatial layout. Many farmers complaint about inconveniences of farming caused by a long distance between building lots and farmlands or about several issues in regional health planning, such as deficiency of sewage and drainage. Their unwelcome attitude towards urbanization is considered to be a grand barrier of development.

\subsection{Development prospects of urbanization become unclear by trends of rural depopulation.}

At present, everyone has his ambition towards high - quality living and it turns out to be the beginning of population migration. A lot of countrymen, most of whom are young people, are leaving their hometowns to pursue better lives in city. Only the aged and children are left behind in countryside and both of them generally refuse to cultivate any corps, resulting in lot of land idle and stagnated development of agriculture.

\section{Development of Rural E-Commerce Has a Wide Significance Towards New-Type Urbanization in China}

\subsection{Narrow the income gap between city and country by increasing rural incomes through a variety of channels}

Rural e-commerce, which has offered a smooth market channel for corps, is helpful to build up a national sales network of agriculture products. With this modern platform, farmers are able to develop an effective sales planning. Therefore, it is possible to narrow the income gap between city and country by raising rural incomes through such a steady market channel. 
Promote the integration of rural products, so farmers can co-operate with each other rather than selling their products individually. Moreover, it is an effective measure to accelerate the development of urbanization. Each village can highlight its own industrial characteristics. In addition, electronic commerce is permitting direct communication between the buyer and the seller. In this way, both of them can save time and money without the middleman. More importantly, products can retain freshness when they are sent to customers.

\subsection{In-situ urbanization is conducive to balance population distributions in cities and rural areas.}

In-situ urbanization means the construction of a new countryside. The keynote of this urbanization policy is the improvement of industrial structure in rural areas and a boost of local economy would be expected. It is an effective way to balance population distributions in cities and rural areas. It can be beneficial to attract young people to work in country and raise hopes that huge population pressure in big cities may be greatly relieved soon. Most importantly, it may reduce employment pressure in big cities.

\subsection{Rural areas can develop at the same pace with cities by achieving informatization.}

Development of e-commerce has improved the poor condition of information flow in rural areas. Internet is a grand platform collecting all people and resources together, where everyone may obtain what he needs and make commodity trades with someone else.Thanks to internet and e-commerce business, links between cites and countries are getting closer and closer, resulting in a strong mutual communication and making progress together.

\section{Difficulties in Developing Rural E-commerce}

\subsection{Farmers do not have clear definitions of internet and e-commerce business}

Statistics on comparison of educational background between cities and rural areas has been presented as follows:

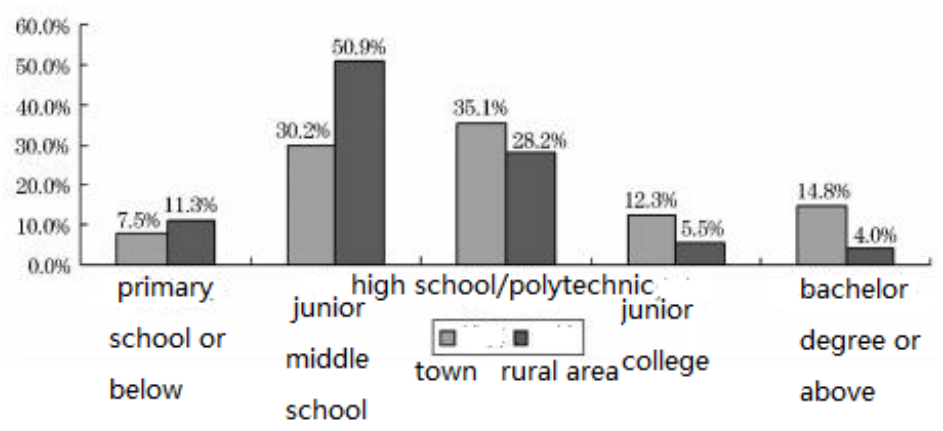

Fig. 1 comparison of educational background between cities and rural areas

From the histogram above, we can see that most of rural netizens have not received education higher than junior middle school. They don't have a comprehensive understanding towards internet and are not clear about the potential commercial value either. Limited by their educational background, farmers don't have a strong ability of learning and mastery of new knowledge . They take a skeptical attitude towards electronic products and cannot trust online payment systems, such as Ali-pay etc.

\subsection{Rural infrastructure and logistics system have weak and unstable foundations, comparing} to those in cities.

A major obstacle is short of infrastructure and modern logistics system. Take express delivery service (EMS) for example, which can be found nearly everywhere in cities.However in many rural areas, people can choose nothing but EMS, which offers a delivery service with a much higher price. In addition, the poor infrastructure construction in countryside has brought about much inconveniences for e-commerce development. In many rural regions, even roads have not been build up nowadays so farmers have to deliver their products by wooden cart. Heavy delivery work exhausts them. 


\subsection{The rough-wrought agricultural products are short of quality standards. The existence of various standards will somehow restrict development of e-commerce.}

Due to environmental constraints, crops usually belong to rough-wrought products. We all know that corps, especially fresh items like fruits, need to be processed as to prevent decay. Difficulties in preservation are considered to be a great resistance to the development of rural e-commerce. Moreover, quality standards of corps have not been completed. Products qualities have to be tested based on people's experience.

\subsection{Without support of experienced professionals, development of e-commerce is limited.}

Unlike the ordinary business, rural e-commerce has its own features. Employees are required to master basic commercial knowledge. More importantly, they have to be quite familiar with local culture and customs. Besides that, they need to know much about production process of corps and local special products. However, in reality experienced professionals are hard to discover and cultivate in rural areas. Few people would like to live in countryside which belongs to the underdeveloped region and local people suffers a lot from poverty. On the other hand, young people can hardly bear the slow and boring life style there. Then they choose to leave and start a new life in cites. It is difficult to cultivate or pick up some professionals among old people and children left behind in countries with poor learning capacity.

\section{How to Promote the Development of Rural E-Commerce and New Urbanization}

\subsection{To build roads}

As a previous experience, desiring to be rich needs to build a road first, and a main cause of poverty is due to environmental occlusion in many rural areas of China, so for a region in order to develop the top priority is to build roads. In many areas, people's crops can only choose to market their own products because of the occlusion, so that the life mode is still very old, the local economy is difficult to develop, people's lives are always struggling at the bottom, and even some people are hard to go out to see the world.If there is no unimpeded road, even the e-commerce is hard to save our country's agriculture, because without access it will be difficult to transport crops outside, and to complete the transactions even if there is advanced e-commerce.

\subsection{To plan the rural e-commerce and new urbanization to increase the development efforts}

First of all, government agencies need to attach great importance to the development of rural e-commerce, planning future development of commerce in rural areas and new rural construction and the future direction of rural e-commerce development, and constantly increase the development efforts. Only under its well guidance, can people keep pace with the government and put the new urbanization in the first place to promote rural development. Therefore, increased investment is needed for the state to improve the status of Chinese information backwardness in rural areas, to implant the idea of information technology into the minds of each farmers, making them recognize the need for developing e-commerce, as well as its market in the future.Only in this way, will the farmers enable to increase interests in e-commerce, willing to keep up with the pace of the times to seek development in E-commerce.

\subsection{To take rural E-commerce as a medium, combined with all forces to jointly promote China's new urbanization}

The E-commerce as a medium with high integration of enterprises, market and social forces in all aspects, makes the e-commerce market more dynamic. Not as an independent individual, e-commerce needs joint efforts of all aspects of society.Only work together can e-commerce in all walks of life promote, making the market more and more powerful, promoting e-commerce into crop trading, rural life, agriculture and handicraft industry. Furthermore, the development in agriculture and handicraft industry can promote the pace of urbanization with advanced e-commerce to realize urbanization as soon as possible. 


\subsection{To enhance the knowledge structure of farmers, making them realize the significance of E-commerce to promote its development in rural areas}

Education is essential in current rural areas. Due to the backward production pattern, the farmers, with backward knowledge structure often do neither realize the meaning of e-commerce in daily production, nor trust network transactions. In consideration of this, improving the rural knowledge system is necessary which can be performed by well publicizing rural e-commerce success stories, making people clearly understand E-commerce and its value.In addition, they also need to be trained so that can have an insight into the outside market through the network, communicate with the buyers to achieve independent transactions, and be more active in joining the electronic trading boom.

\subsection{To retain the original characteristics of urban and rural areas, adjust the coordination of urban and rural development}

In recent years, serious polarization in China has been intensified, which is reflected in people's income levels and lifestyles, and has brought great difficulties in the development of urbanization. This requires local governments construct urbanization belongs to local ares according to local characteristics, that is, local urbanization.In the light of the requirement of local urbanization, the original local characteristics shall be retained in order to build more characteristics of the village in the construction of urbanization at the same time, making rural development more promising. The coordination of urban and rural development is also needed, making the town and the city realize common development.

\section{Conclusion}

In the 21st century, electronic transactions have gone into millions of households when internet products like Taobao and Alipay are booming. Although each one has learned to use shopping online, the essential is how to link e-commerce to rural development to broken the traditional trading model, and to reduce the restrictions on crops brought by the environment, so that the rapid development of rural economy can strive to keep up with the pace of urban economy. Certainly, we will encounter a lot of problems on the road of promoting the development of rural e-commerce, but we must believe that our strength gathered from all aspects.In this way, we can solve the problems on the way as soon as possible, and achieve common development of ruralization and urbanization.

\section{References}

[1]. Li Lingfang. E-commerce in Rural Areas[J]. Journal of the Fujian Provincial Committee Party School,2013,(5):70-74

[2]. Ni Pengfei. The Basic Pattern,Specific Path and Promotion Strategy of New Urbanization[J]. Journal of Jianghai, 2013,(1):87-94.

[3]. Chinese Academy of Social Sciences Institute of Finance and Economics Research Group.E-commerce: the New Engine of China 's Economic Development[J].Truth seeking, 2013,(11):15-17.

[4]. Liu Qiqiang, Ding Bin. Rural E-commerce and New Urbanization Construction[J]. China 's National Conditions and Strength, 2016(1):22-23.

[5]. Duan Huijun, Tang Feifei. Agricultural E - commerce Development Model under New Urbanization---Example by Hengyang in Hunan Province[J] Daily Fortune, 2016(13):75-76.

[6]. Zhang Jing, Jiang Shuihua. Research on the Innovation of Agricultural E-Commerce Model in the New Countryside Construction-Example by Xiamen[J]. Journal of Hubei University of Science and Technology, 2016, 36(3):45-47. 